\title{
Ejercicios de memoria: sobre los modos de reconstruir la memoria vanguardista en Oswald de Andrade, Jorge Luis Borges, Mário de Andrade y Oliverio Girondo Mario Cámara*
}

\section{Resumen:}

El presente artículo se propone un análisis de una serie de textos de Oswald de Andrade, Jorge Luis Borges, Mário de Andrade y Oliverio Girondo referidos a sus producciones vanguardistas. El análisis de los textos tiene por objetivo indagar sobre los modos en que, a partir de dichos testimonios, memorias y reflexiones, se han pensado las vanguardias literarias de los años veinte en Argentina y Brasil, y se han colocado en sus respectivos campos culturales.

\section{Palabras claves:}

Vanguardia, memoria, campo cultural

\begin{abstract}
Hacia 1905, Hermann Bahr decidió: El único deber, ser moderno. Veintitantos años después, yo me impuse también esa obligación del todo superflua. Ser moderno es ser contemporáneo, ser actual; todos fatalmente lo somos.
\end{abstract}

Jorge Luis Borges

Para quien, siendo argentino, se ha aventurado por las manifestaciones de la cultura brasileña, y ha tenido la dicha de profundizar en ella, siempre resulta tentador establecer comparaciones. Qué enorme tentación surge entonces cuando comenzamos a indagar en las vanguardias de los años veinte, cuan sencillas, por no ello menos engañosas, comparaciones nos vienen a la mente. Casi nos atreveríamos a afirmar que Mário de Andrade, por su trayectoria, por su gravedad, por su erudición fue una especie de Jorge Luis Borges o que Oliverio Girondo, en su empeño constante por la vanguardia, en su modo

\footnotetext{
* Dr. Profesor de Literatura Brasileña y Portuguesa, Universidad de Buenos Aires.
} 
juguetón de promocionarse, nos resulta semejante a Oswald de Andrade. Sin embargo, ha poco de andar, ha poco de leer, pese a algunas coincidencias fundamentales, surgen las inevitables diferencias. Sin embargo, estas diferencias no niegan las conexiones que se pudieron haber establecido entre estos movimientos, y como punto a destacar aquí figuran los textos de Mário de Andrade en relación a la literatura argentina (RODRIGUEZ MONEGAL, 1978) o la colaboración de Norah Borges en la revista Verde, que se editaba en la pequeña ciudad de Cataguazes.

Probablemente la diferencia a la que hago mención tenga que ver con los contextos históricos en los cuales surgen los movimientos de vanguardia, en la relación que estos establecieron con la tradición y con los movimientos de vanguardia europeos -no olvidemos los coqueteos, contradictorios por cierto, de los modernistas brasileños con el futurismo de Marinetti-, en el desarrollo de los proyectos individuales de algunos de los integrantes de esas vanguardias y de un modo prospectivo, en la presencia en tanto fuerza actuante o simple relato en la vida cultural de Brasil y Argentina.

Teniendo como objetivo un trabajo comparativo que, en la búsqueda de las diferencias, permita iluminar algunos procesos culturales de vanguardia de los dos países, me propongo abordar una serie de intervenciones críticas de Jorge Luis Borges, Oliverio Girondo, Mario de Andrade y Oswald de Andrade. Dichas intervenciones están compuestas de evocaciones, conferencias, artículos críticos que hagan referencia directa o aludan a los movimientos de vanguardia, martinfierrismo y ultraísmo, en el caso argentino y modernismo, en el brasileño, de los cuales aquellos fueron protagonistas. De este modo, confío en que la elección de estos relatos retrospectivos, pese a las omisiones deliberadas o involuntarias, nos permitirán detectar, en sus sucesivas transfiguraciones o reiteraciones, los contornos de proyectos que, aunque grupales, tuvieron importantes matices personales. Por otra parte, espero que la comparación entre este conjunto de intervenciones permita reflexionar acerca de los modos en que se construyen, circulan y se legitiman las narraciones sobre las vanguardias locales en países como Argentina y Brasil.

\section{Oswald de Andrade: recordando la vanguardia aun antes de la vanguardia 1923 - 1954}

Apenas pasado un año de la celebración de la Semana de Arte Moderno en 1922, Oswald de Andrade viajó a Europa y brindó una conferencia en la universidad de La Sorbonne, titulada "O esforço intelectual do Brasil 
contemporâneo", ${ }^{1}$ que además de ser un texto programático del modernismo, desde el presente puede ser leído como la primera rememoración del mismo. Pero hubo otras rememoraciones de parte de Oswald, el texto publicado en 1937, en O Estado de São Paulo, titulado "O divisor das águas modernistas"; 2 una conferencia realizada en San Pablo, en 1945, titulada "Informe sobre o modernismo"; ${ }^{3}$ un discurso leído en agradecimiento por sus sesenta años y publicado en el Jornal de São Paulo en 1950, titulado "Sex-appeal-genário"; ${ }^{4}$ un texto publicado en Correio da Manhã, en 1951, titulado "Notas para o meu diario confessional" ${ }^{\prime 5}$ y un texto publicado en la revista Anhembi en 1954, titulado "O modernismo" (1991).

En todas ellas, pese a ciertas variaciones, de quién fue la paternidad del movimiento ${ }^{6} \mathrm{o}$, evidentemente, diferentes evaluaciones sobre el contexto de la enunciación, se ha mantenido una misma caracterización sobre el movimiento y su incidencia sobre la cultura del Brasil, y tal vez hasta más importante, sobre el futuro de ella. Sobre este último aspecto quisiera extraer algunas citas y luego referirme a ellas.

En el primer artículo mencionado, Oswald traza una historia, construye un relato que desemboca en los años veinte, en San Pablo. Por ello va a comenzar por la etapa de la conquista: "Houve, pois, na formação inicial do Brasil, três elementos diversos: o índio, o português e o padre latino. O negro veio da África, pouco tempo depois" (1991, p. 29). Portugués, negro e indio, todos bajo la égida de los padres latinos, de los evangelizadores. Mediante el cura evangelizador se instauró la escolástica como base del pensamiento brasileño. Sin embargo, la escolástica será luego atacada, o más bien superada. En el relato que traza Oswald de Andrade existe un plano filosófico, que tiene que ver con la recuperación de una capacidad deísta del Brasil y por ello finaliza afirmando "O Brasil, sob o céu deísta, toma conciencia do seu futuro" (1991, p. 38). Y, por otra parte, describe un plano artístico-literario en el que Basilio da Gama, Gonçalves Dias y José de Alencar son mencionados como precursores de

\footnotetext{
11923 resulta una fecha crucial para el modernismo brasileño. Es el año en que Oswald de Andrade viaja a París y brinda su famosa conferencia en La Sorbonne. Oswald de Andrade toma contacto con el primitivismo europeo y es a través de este que consigue darle una flexión nacional al modernismo. En 1924 redacta el primer manifiesto vanguardista brasileño "Pau Brasil".

${ }^{2}$ In O Estado de São Paulo, Suplemento de Rotogravura. São Paulo, septiembre de 1937, p. 4

${ }^{3}$ Conferencia realizada en São Paulo el 15 de octubre de 1945, IEL-Unicamp.

${ }^{4}$ Discurso de agradecimiento por el homenaje realizado a los sesenta años de Oswald de Andrade, en el Automóvil Club de San Pablo, marzo de 1950. Publicado en el Jornal de São Paulo, 26 de marzo de 1950.

${ }^{5}$ Texto publicado en el Correio da Manhã, 15 de junio de 1951.

6 En "Sex-Appeal-Genário" va a decir, "Eu estava quieto, jogando sinuca, quando me apareceu não uma 'nega maluca', mas uma dúzia de negas malucas, querendo me atribuir a paternidade de múltiplas coisas que se produziam nesta cidade - 'Esse filho é seu'! Tratava-se da Semana de Arte Moderna" (p. 128).
} 
una cultura nacional, pero el máximo exponente es Machado de Assis, al que sin embargo,

A reação contra a loquacidade sul-americana operou-se no Brasil por intermédio do sangue negro. O negro é um elemento realista. Isto observou-se ultimamente nas indústrias decorativas de Dakar, na estatuária africana, posta em relevo por Picasso, Derain, André Lothe e outros artistas célebres de Paris, na antologia, tão completa, de Blaise Cendrars. De resto, ele, que vinha de África, não podia maravilhar-se diante da nossa paisagem. O português, ao chegar fazia sonetos, e o negro, por seu turno, a fim de expressar suas alegrias ou suas mágoas, rufava nos urucungos... (1991, p. 32)

Es decir, el negro traído de África no se sorprende con la exhuberancia del trópico, no hay un arrebato frente al trópico. En este sentido, Machado de Assis fue un equilibrio perfecto por la sangre negra. $Y$ luego, con carácter asertivo va a decir,

A contribuição de materiais destinados a uma literatura nacional definitiva foi fornecida por Inglês de Sousa, que fez um riquíssimo quadro das sociedades amazônicas, por Afrânio Peixoto e pelos naturalistas Aluísio de Azevedo e Júlia Lopes de Almeida. (1991, p.32)

En su conferencia Oswald de Andrade reconoce un legado, existe algo así como una tradición a la cual acudir. Pero se trata de una riqueza incompleta, a la que es preciso adicionarle "expresión" y "forma": "Dada nossa matéria psicológica e nosso sentimento étnico, a obra do Brasil contemporâneo consiste em aliar a estas riquezas adquiridas uma expressão e uma forma que podem dirigir nossa arte para o apogeu" (1991, p. 34). Hacen falta escritores que puedan dotar de una lengua a esa materia y a ese sentimiento étnico. Hace falta una lengua nacional que se exprese en una forma que le sea propia. Por otra parte, ese apogeo del que habla es el que resultó de los primeros textos de Mário de Andrade, que creó una poesía "desconhecida no Brasil", es también Manuel Bandeira, Ronald de Carvalho y Menotti del Picchia, entre otros. Todos ellos forman parte de una "geração construtora".

En 1937, en "O divisor das águas modernistas", con el modernismo disuelto como movimiento, con sus integrantes en lugares diferentes $\mathrm{y}$, muchas veces, enfrentados, Oswald es menos condescendiente con el pasado literario de Brasil a la vez que realza la importancia de la Semana: 
Qualquer apreciação das letras brasileiras deve ser hoje precedida do exame de revolta manifesta de 1922. Essa famosa Semana foi uma parada de conjunto, feita para protestar contra a decadência da literatura e da arte no Brasil. (1991, p. 53)

Se trata de un recuerdo que no duda en calificar de "heroica" aquella primera noche, aquella que dio inicio a la Semana de Arte Moderna. En este sentido, y como podremos luego apreciar, se diferencia de Mário de Andrade aunque comparten, de un modo paradójico, un punto en común. La Semana fue una estación de llegada. Pero para Oswald fue una llegada triunfante, la coronación de un proceso que había comenzado años atrás, mientras que para Mario fue el inicio del fin, el comienzo de la etapa destructiva del movimiento.

Ocho años después, en 1945 -Mário de Andrade había muerto pocos meses antes -, Oswald pronuncia su conferencia "Informe sobre o modernismo". Se trata de un año clave pues rompe con el partido comunista ${ }^{7}$ y concursa y conquista la cátedra de Literatura en la Facultad de Filosofía con la tesis "La Arcadia y la Inconfidencia". En aquel informe recupera por ejemplo a Machado de Assis, que desde el 23 no había sido vuelto a nombrar. De todos modos, escoge la imagen del desierto para referirse a la aparición del modernismo:

O Brasil possui três séculos de literatura ao par. Desde Gregório de Matos através dos inconfidentes e dos românticos, nos mantemos com segurança, respondendo com Castro Alves a presença de Whitman na América e produzindo no deserto inicial do século XX as duas figuras que fazem o pórtico da nossa era moderna - Machado de Assis e Euclides da Cunha. Deles e de alguns outros como Raul Pompéia e Aluísio, longinquamente decorreria o que ate hoje realizamos. (1991, p. 98)

Destaquemos aquí la palabra "desierto" y la palabra "pórtico", el modernismo, de este modo, es presentado como el territorio de llegada después de la nada. Sin embargo, la mención de nada menos que de cuatro nombres, Machado de Assis, Euclides da Cunha, Raul Pompeia y Aluísio Azevedo, conforman una cifra nada despreciable frente a la cual la palabra "desierto" suena desmesurada.

Entre 1950 y 1954 Oswald produce tres artículos sobre el Modernismo. En "Sexappeal-genário", de 1950, reitera, una vez más que "O Brasil teve aí o seu cálido divisor de águas" (1991, p. 134). Frente a aquella división, el artículo reflexiona amargamente sobre el presente, al que encuentra oscuro y

\footnotetext{
7 Dirá de su ruptura: "El centro de la Revolución no estaba en el proletariado y sí en la burguesía aliadófila y antifascista, lista para entregarse y seguir a Prestes". In Escritos antropófagos. Selección, cronología y postfacio Gonzalo Moisés Aguilar y Alejandra Laera. Buenos Aires: Corregidor, 2002, p. 13.
} 
mercantilizado. El mismo diagnóstico aparece en "Notas para o meu diário confessional", allí dirá "Hoje o Brasil mergulhou na indiferença e na ignorância das próprias conquistas" (1991, p. 138). En su último texto, "O modernismo", de 1954, afirma,

Desse modo, por toda parte alentava-se o movimento que eclodiu no movimento de 22 . Esse foi 0 instante útil. Festejava-se o centenário da nossa independência política. Exposições e festas por toda parte. (1991, p.124)

Y un poco más adelante, lo reitera,

Assim, um conjunto feliz de circunstâncias, entre as quais a presença entre nós de dois bons padrinhos, Graça Aranha e Paulo Prado, fez eclodir a Semana no ano em que se comemorava o primeiro centenário da independência nacional. (1991, p. 127)

Como hemos podido observar, Oswald de Andrade se propuso definir una literatura y una cultura a partir del modernismo. La vanguardia brasileña fue un puerto de llegada y por lo tanto su predicamento para el futuro resulta irreversible.

\section{Jorge Luis Borges: olvidando la vanguardia 1925-1932}

La recuperación del Borges vanguardista sólo ha sido posible luego de su muerte, cuando han sido reeditados sus primeros libros -muchos de los cuales estaban fuera de circulación por expreso deseo del autor-, y mucha de su producción dispersa, fundamentalmente entre 1919 y $1929 .{ }^{8}$ Podríamos afirmar que ya en 1925 Borges no sólo había dejado de ser vanguardista sino que en sus menciones a ella siempre tiene algún adjetivo desdeñoso o alguna reflexión que marca sus límites. Se torna dificultoso, de todos modos, encontrar algún texto relevante en el que reflexione sobre su participación en el ultraísmo y en el periódico Martín Fierro. En su libro Inquisiciones, publicado por primera vez en 1925, y luego sólo póstumamente, encontramos un ensayo titulado "La traducción de un incidente" y relata, en un tono levemente melancólico, lo que acentúa la impresión de algo que sucedió hace mucho tiempo, e irónico, las disputas poéticas entre los grupos que respondían alternativamente a los españoles Ramón Gomez de la Serna y a Rafael Cansinos Asséns y las da por finalizadas. Recordemos que Cansinos Asséns era una figura central para el

${ }^{8}$ Me refiero a Textos recobrados 1919-1929. España: Emecé editores, 1997. 
movimiento ultraísta español. Pero lo más interesante consiste en el párrafo final del artículo, en el que Borges señala,

Europa nos ha dado sus clásicos, que asimismo son de nosotros. Grandioso y manirroto es el don; no sé si podemos pedirle más. Creo que nuestros poetas no deben acallar la esencia de anhelar de su alma y la dolorida y gustosísima tierra criolla donde discurren sus días. Creo que deberían nuestros versos tener saber de patria, como guitarra que sabe a soledades y a campo y a poniente detrás de un trebolar. $(1997$, p. 21)

Vemos en la primera parte del fragmento un enunciado que Borges repetirá en su ensayo "El escritor argentino y la tradición", la apropiación de una tradición que nos pertenece al igual que a los europeos. Pero al mismo tiempo, la referencia, hacia el final, de la guitarra, el campo y el trébol, le da al artículo una inflexión nacional que, sin dudas, da por finalizada la etapa vanguardista de Borges. $^{9}$

Por otra parte, creo que siguiendo el rastro de algunas de sus reflexiones acerca de la lengua nacional y la tradición, de una manera indirecta y, muchas veces, solapada, Borges ajusta sus cuentas con las vanguardias argentinas y prepara su colocación dentro del campo cultural argentino.

No debemos olvidar que en los años inmediatamente posteriores a su regreso a Buenos Aires en 1920, Borges tuvo una producción sorprendente. Publicó los libros de poesía Fervor de Buenos Aires (1923); Luna de enfrente (1925); Cuaderno San Martín (1929) y los libros de ensayos El tamaño de mi esperanza (1926) y El idioma de los argentinos (1928), además del ya mencionado Inquisiciones (1925). En 1921 fundó la revista Prisma y en 1922 la revista Proa, a la vez que fue un activo colaborador de Martín Fierro. Considero, sin embargo, que hacia 1932 Borges ya se había separado no sólo de las vanguardias, que por otra parte ya habían dejado de existir como tales, sino de toda una poética de la cual va a renegar. $Y$ creo, que podemos presenciar esa nueva postura en el ensayo publicado ese mismo año, titulado "El escritor argentino y la tradición" (1985).

Nos podríamos preguntar, cuál sería la relación entre una problemática relacionada con la tradición y la relectura de las vanguardias. Considero que las vanguardias, la argentina y la brasileña, y todas las vanguardias en general, se

\footnotetext{
9 Se podría leer el ensayo que le dedica a Eduardo González Lanuza, también publicado en Inquisiciones como una crítica velada al Ultraísmo o al menos una posición ambigua que Borges plasma del siguiente modo: "Gonzáles ha logrado el libro nuestro, el de nuestra hazaña en el tiempo y el de nuestra derrota en lo absoluto. Derrota, pues las más de las veces no hay una intuición entrañable vivificando sus metáforas; hazaña, pues el reemplazo de las palabras lujosas del rubenismo por las de la distancia y el anhelo es, hoy por hoy, una hermosura".
} 
proponen no sólo como una ruptura con una determinada tradición sino, también, como fundadoras de una nueva tradición. La recuperación del barroco brasileño funcionaría de ese modo para los modernistas brasileños y tal vez, sin barroco de donde aferrarse, Pedro Figari y Ricardo Guiraldes, aunque vivos y aun produciendo, cumplieron el rol del "pasado nacional" para la vanguardia argentina. En todo caso, la tradición era un problema para las vanguardias. El modernismo debía lidiar con los parnasianos, o como diría Oswald de Andrade en su manifiesto Pau Brasil, con "el lado docto", con el "hablar difícil"; los martinfierristas debieron lidiar con los Lugones, los Anglada Camarasa. Frente a ello, Borges va a señalar que no existe un tal problema como el del escritor argentino y la tradición. Proclama que sé es fatalmente argentino y sé es, por lo tanto, fatalmente contemporáneo. Unos versos de Enrique Banchs, y prestemos atención, no de Girondo, no de Lanuza, no de Olivari, le sirven como ejemplo de lo que pretende decir. Hay allí un cierto pudor que es típicamente argentino. Podríamos traducir ese "pudor" como una cierta dicción que sería típicamente argentina. Luego de ello, aparece su famosa frase "El culto argentino del color local es un reciente culto europeo que los nacionalistas deberían rechazar por foráneo" (1985, p. 270).

La postulación, una verdadera paradoja, pone al nacionalismo en un camino sin salida, pues cómo ser nacionalista sin adherir a las premisas del nacionalismo. Sin embargo, podemos pensar, pero el martinfierrismo era una vanguardia cosmopolita. Lo cual, de alguna manera era verdad, pero en algunos de sus colaboradores había una preocupación por lo nacional, por una dicción verdaderamente nacional, y entre ellos sin dudas podemos contar a Borges, cuyo primer libro de poesía, como ya lo hemos mencionado, se titulaba nada menos que Fervor de Buenos Aires. En una alusión a sus obras vanguardistas, ${ }^{10}$ Borges apunta:

en libros ahora felizmente olvidados, traté de redactar el sabor, la esencia de los barrios extremos de Buenos Aires; naturalmente abundé en palabras locales, no prescindí de

\footnotetext{
10 Borges no dejará de tener comentarios negativos acerca de su pasado vanguardista, de sus compañeros de ruta y de las vanguardias en general. En entrevista concedida a Fernando Sorrentino dirá en relación al ultraismo "Si, ese grupo lo fundó Rafael Cansinos Assens y yo ya me daba cuenta de que él lo había hecho un poco irónicamente. Fue un poco en broma como la polémica de Florida y Boedo, por ejemplo, que veo que se toma en serio ahora (p. 26)". Y luego en relación a Oliverio Girondo, "Es que Oliverio Girondo, como escritor, nunca contó mucho. Oliverio Girondo financió la revista Martín Fierro, pero la obra personal de él...Yo no creo que él le haya dado ninguna importancia tampoco. Creo que a él le interesaba más la tipografía, la imprenta...Lo que él escribía, ¿qué era? Más o menos greguerías, en fin..." (p. 27). In: Siete conversaciones con Jorge Luis Borges. Buenos Aires: Editorial El Ateneo, 2001.
} 
palabras como cuchilleros, milonga, tapia, y otras, y escribí así aquellos olvidables y olvidados libros. (1985, p. 270)

El artículo deconstruye otros dos postulados. Aquel que propone vincular al escritor argentino a la tradición española y aquel que supone que los argentinos serían puros a partir de su desconexión de Europa. ¿Cuál es la tradición argentina?, se pregunta finalmente:

Todo lo que hagamos con felicidad los escritores argentinos pertenecerá a la tradición argentina, de igual modo que el hecho de tratar temas italianos pertenece a la tradición de Inglaterra por obra de Chaucer y de Shakespeare. (1985, p. 273)

Hay una propuesta de "abandonarse a un sueño voluntario que es la creación artística" para que de allí surja lo argentino. El último cuestionamiento que podría surgir sería el siguiente, pero entonces Borges admite una relación con la cultura universal, sin condicionamientos y ¿no era eso lo que se proponía la vanguardia?, la respuesta es no. La vanguardia tenía un pensamiento sobre el presente y sobre el futuro, construía otra tradición pero su direccionamiento, anclado firmemente en el presente, se dirigía al futuro. No podemos afirmar a partir de este artículo que en Borges haya un pensamiento no sobre el presente ni sobre el futuro, tampoco se trata de un artículo nostálgico. Creo entender que Borges ya está diseñando su perfil de escritor clásico pero de un clasicismo tramposo, puesto que su postura de utilizar el reservorio de toda la cultura occidental tiene rasgos de lo que luego se conocería como posmodernismo. En todo caso, en cuanto al tema que nos ocupa, su única mención a sus libros de vanguardia es desdeñosa y el conjunto del artículo puede ser leído como un ajuste de cuentas con aquel pasado.

\section{Mário de Andrade: estertores de casi tres décadas 1917-1942}

La conferencia que Mário de Andrade pronunció en 1942, cuando se cumplían veinte años de la Semana de Arte Moderna, en la Casa do Estudante, en Río de Janeiro, titulada "El movimiento modernista"(1979), ha sido leída como un ajuste de cuentas con el movimiento modernista que él integró, ${ }^{11}$ teniendo en cuenta el contexto en el cual fue pronunciada. Es el año en el cual Brasil le

\footnotetext{
11 Un año antes, en 1941, Mário de Andrade, escribió "Elegía de abril", en el cual comenzaba a ajustar cuentas con el pasado, remarcando especialmente la falta de un compromiso por parte del intelectual con la situación que le había tocado vivir. "A inconsciência de minha geração, se não a absolve, a fataliza - homem de um fim-de-século em que, meu Deus! No Brasil não repercutia nada! (187). In: Aspectos da literatura brasileira. San Pablo: Globo, 1976.
} 
declara la guerra a Alemania, en el contexto de la Segunda Guerra Mundial y es el año en que Mário de Andrade regresa a San Pablo luego de un exilio interno en Río de Janeiro.

De todas maneras, más allá de la evaluación crítica que Mário de Andrade, efectivamente realizó, quisiera centrarme en el tono afectivo que recorre el texto, en el dramatismo con que pregona lo que parece ser un arrepentimiento, como cuando señala que más que de ejemplo el modernismo debía ser una lección para los artistas del presente. Sospecho que allí, en la gravedad de sus evaluaciones, resurge la importancia que la crítica realizada, de algún modo, había pretendido neutralizar.

Sin embargo, cabe aclarar dos cuestiones, el modernismo fue para Mario de Andrade algo más vasto que el movimiento artístico aunque adquirió en este su manifestación privilegiada, que luego crearía un "estado del espíritu nacional". Es decir, el modernismo fue un conjunto de situaciones epocales que tenían que ver con transformaciones de orden histórico-políticas y "la Semana de Arte Moderno fue el vocero colectivo principal" (1979, p. 292). En lo que respecta al movimiento artístico propiamente dicho, Mario estableció una periodización que lo dividía en dos etapas. La primera de ellas, a la que definió como el periodo verdaderamente heroico, fue de 1917, cuando el grupo se centró alrededor de la escultora Anita Malfatti, sin embargo, ese mismo periodo el grupo se destacó por su aristocratismo,

por su espíritu extremadamente aventurero, por su internacionalismo modernista, por su nacionalismo exaltado, por su gratitud antipopular, por su dogmatismo prepotente, era una aristocracia del espíritu. (1979, p. 297)

Mientras que la Semana de Arte Moderno abrió la segunda etapa del movimiento modernista, el período realmente destructor, que se continuó hasta 1930. Establecida esta primera frontera, a uno y otro lado se acumulan las adjetivaciones. La exaltación, el delirio ingenuo de grandeza, las conmociones prodigiosas, la pureza y la libertad pertenecen al primer periodo; la disolución, la orgía, el arrebato, el jolgorio, características que debilitaban la capacidad creadora y que definieron el segundo periodo.

Doctrinarios, en la embriaguez de mil y una teorías, salvando al Brasil, inventando el mundo, en realidad no hacíamos otra cosa que consumirnos a nosotros mismos, en el culto amargo, casi delirante, del placer. (1979, p. 301) 
Lo que pretendo sostener, con lo expuesto hasta el momento, es que ya sea en la mirada idílica con que Mário de Andrade evocaba el primer período como el carácter autoflagelatorio con que nos describió el segundo momento, lejos estaba de subestimar aquellos años. Por otra parte, y entiendo que esto refuerza mi argumentación, caracterizados los periodos, Mário señalaba:

El movimiento de Inteligencia que representamos, en su etapa verdaderamente 'modernista', no fue, en Brasil, factor de cambios político-sociales posteriores a él. Fue esencialmente un elemento de preparación; el creador de un estado de espíritu revolucionario y de un sentimiento de explosión. (1979, p. 301)

Es decir, si bien no fueron un factor de cambios, si lo fueron de preparación de esos cambios. Ese estado de espíritu revolucionario al que hace referencia se reflejó en las transformaciones políticas que a partir de 1930 experimentaría Brasil. De hecho, a partir de la asunción de Getúlio Vargas, se diseñaría en un nuevo estado en el país, que incluiría nuevas leyes, nuevos ministerios y una nueva distribución del poder. Getúlio Vargas, siendo del sur, rompió con la hegemonía que durante la República Velha habían sostenido San Pablo y Minas Gerais. La asunción de Vargas radicalizó las posturas de algunos de los integrantes del Modernismo, como por ejemplo Oswald de Andrade.

Cuando Mário de Andrade considera que a partir de 1930 comenzó otra etapa para los intelectuales brasileños, probablemente menos exhibicionista pero también menos destructiva, está pensando en la efectividad de los modos en que se desenvolvió la vanguardia, en la posible descendencia de la misma. Al mismo tiempo, el destino del movimiento modernista cumplió un objetivo y una vez cumplido ya no tenía razón de ser.

Al examinar qué impuso efectivamente el movimiento modernista, Mario destacó tres elementos: el derecho permanente a la investigación estética; la actualización de la inteligencia artística brasileña; y la estabilización de una conciencia creadora nacional. Pero aquellos tres elementos, que por primera vez aparecen simultáneamente en la historia de Brasil, no fueron lo suficientemente aprovechados. Hubo en el período un excesivo individualismo que se manifestaba en el lema modernista "iNo hay escuelas!", y esto, por cierto, "perjudicó mucho la eficiencia creadora del movimiento" (1979, p. 303).

Mário también critica los modos en que se manifestó la reflexión sobre lo nacional, el ufanismo que emergía en "doctrinas y manifiestos" (claro, no se puede dejar de pensar en los manifiestos de Oswald de Andrade) y entonces va 
a señalar "El estandarte más colorido de esta radicación en la patria fue la investigación de la 'lengua brasileña'. Pero fue tal vez un falso boato. En verdad, pese a las apariencias y al estruendo que hacen ahora ciertas santidades de última hora, nosotros seguimos siendo tan esclavos de la gramática lusa como cualquier portugués". Colocándose en el presente, comprueba con agrado que a los brasileños se les ha olvidado la afición a lo nacionalista, como si el nacionalismo, no ingenuo ni acrítico por cierto, reclamado por Mário, hubiera sido introyectado y se hubiera normalizado en un registro que dejó atrás la tentación del ufanismo.

Y entonces sí, concede: "Respecto a la conquista del derecho permanente a la investigación estética, creo que no es posible ninguna contradicción: es la gran victoria del movimiento en el campo del arte" (1979, p. 308). Pero lo dicho no significa ninguna reminiscencia melancólica, Mário se presenta como un escritor que acompaña al presente, probablemente a diferencia de Oswald de Andrade y por ello cree que es en el presente donde se esté dando el primer movimiento de independencia de la inteligencia brasileña. La aserción es enfática pues la reitera: "Esa normalización del espíritu de investigación estética, antiacadémica, pero ya no rebelde ni destructiva, es, a mi ver, la mayor manifestación de independencia y de estabilidad nacional que haya conquistado la Inteligencia brasileña" (1979, p. 308)

En lo que sería una reflexión sobre la tercera de las premisas que puso en juego el modernismo, Mario define, o lo intenta, un lugar para el arte en lo social y una función que el arte cumple o debería cumplir dentro de la sociedad. Se trataría de no quedarse únicamente en la creación hedonista de belleza. Y en este sentido, el modernismo representó un papel contradictorio y precario, afirma: "estoy convencido de que debimos haber dejado de ser especulativos para pasar a ser especuladores" (1979, p. 309). Y luego afirma que los integrantes del modernismo, él incluido, eran los hijos finales de una civilización que ya se acabó. Sin embargo, considera que ha superado, junto a muchos otros, esa etapa destructiva que caracterizó al modernismo.

Más allá de analizar la autocrítica de un integrante del modernismo brasileño, que por otra parte ya ha sido lo suficientemente analizada, quise recorrer el texto para resaltar su dramaticidad puesto que en su impugnación se revela la dimensión de la importancia concedida a aquellos años. El estruendo del fracaso, que en sus propias palabras se traduce como "servir de lección y no de ejemplo", convierte a aquellos años como algo digno de nota. 


\section{Oliverio Girondo: juvenilismo del pasado en 1949}

En 1949, en el acto organizado por la Comisión Directiva de la Sociedad Argentina de Escritores y con motivo de cumplirse veinticinco años de la aparición del periódico Martín Fierro, Córdova Iturburu leyó un texto titulado "El periódico Martín Fierro" (1999), que en realidad había sido escrito por Oliverio Girondo. Recordemos brevemente que Girondo había publicado hacia tres años Campo nuestro y también que comenzaba a tener una gravitación cierta sobre una serie de jóvenes poetas entre los que se pueden mencionar a Enrique Molina, Olga Orozco, Francisco Madariaga, Edgar Bayley y Aldo Pellegrini, entre otros. Dicha gravitación le significaba, luego de un largo período de cierto olvido por parte de la crítica a partir de la publicación de Espantapájaros en 1932, el inicio de un reconocimiento que terminará de concretarse con la publicación, en 1954, de En la masmédula. De tal manera, debemos considerar que tanto la conmemoración como la lectura de la memoria forman parte de este creciente reconocimiento hacia la figura de Oliverio Girondo, esta vez mediado a través del homenaje del periódico Martín Fierro. Oliverio Girondo se proponía tres objetivos en este informe: una síntesis de su desenvolvimiento, de su significado y de su influencia en la literatura y las "Bellas Artes".

El primer dato significativo consiste, precisamente, en esta mediación, que por otra parte es doble, pues la lectura la realizó Córdova Iturburu y la firma del texto fue grupal. Al mismo tiempo, dentro del texto, muchas de las afirmaciones y reflexiones se construyeron a través de la figura retórica de la prosopopeya, es decir, en muchos tramos nos habla el propio periódico investido de una repentina voz y no sus editores, como por ejemplo cuando afirma: "Literariamente, por lo menos, puede afirmarse que Martín Fierro nunca estructuró una estética propia, ni remodeló alguno de los tantos 'ismos' mencionados" (1999, p. 319)

También sorprende el carácter conciliador del documento, como por ejemplo cuando señala que algunos integrantes del periódico incurren en "involuntarias alteraciones de la verdad" (302). El tono conciliador se manifiesta bajo dos aspectos en el discurso, el primero de ellos resalta la energía juvenil de los colaboradores que puede derivar en posturas maximalistas, como si el tiempo fuera, irremediablemente un neutralizador de los impulsos. El segundo aspecto es el relato de una permanente armonía hacia el interior del periódico, capaz de abrigar numerosas orientaciones estéticas cobijadas, básicamente, por el único deseo de modernizar el estado del arte. Se pueden dar numerosos ejemplos de ello, "la franca y cordial camaradería que une a los colaboradores de "Martín 
Fierro" (310), "no es esto lo que motiva, sin embargo, la disgregación del directorio, como tampoco la origina alguna desavenencia entre sus componentes, puesto que siempre los unió la más sincera y fraternal camaradería" (1999, p. 315). Por tal motivo, las razones para la disolución del periódico, o del directorio del periódico que redundará en el cierre del mismo, son calificadas "de índole personal" y están narradas en un registro que a la vez que las justifica no intenta ninguna reflexión crítica sobre las mismas. Dice Girondo,

El primero en invocarlas es Eduardo Bullrich, quien cada día más absorbido por sus ocupaciones profesionales, se separa de la dirección al iniciarse la campaña contra el Museo, por existir motivos privados que le impiden participar en ella, aunque la considere en principio -si no en su forma- plenamente justificada. Unos meses después Girondo se siente acometido por uno de sus frecuentes ataques deambulatorios y decide cortar amarras. Ante tan mal ejemplo, Sergio Piñero precipita el viaje a Europa que incubaba desde tiempo atrás, $y$, en vista de este desbande general Alberto Prebisch abandona la dirección, aunque seguiría colaborando en el periódico hasta su último número. (1999, p. 316)

Dicha declaración escamotea que la disolución se debió, también y en buena medida, a diferencias políticas surgidas a raíz de la creación del "Comité Yrigoyenista de Intelectuales Jóvenes". Mientras que algunos sostenían que el periódico no debía adherir "oficialmente" a la reelección de Hipolito Irigoyen, otros sostenían la necesidad de la participación.

Por sobre las rencillas personales o estéticas, la camaradería parece surgir de la ausencia de una verdadera estética martinfierrista, tal como se propuso, por ejemplo, el modernismo brasileño. En este sentido, cabe destacar que Girondo destaca por sobre todo, el esfuerzo divulgador de la publicación.

Más que por un criterio estético, la generación martinfierrista está unida por una "amplitud de espíritu", "vitalidad", ímpetu combativo", "anhelos de renovación", "humor y desenfado" y "confianza en si misma". Podemos apreciar que en este listado de características que nos entrega Girondo, tal vez a excepción del humorismo, ninguno funciona como una categoría estética. Se trata de proposiciones de carácter reactivo y/o receptivo. Se reacciona contra lo existente y entonces se anhela renovarlo pertrechados de un espíritu combativo que es lo suficientemente amplio para recepcionar que es lo nuevo, sin que quede esclarecido en qué consiste eso nuevo. En otras palabras, no queda claro 
el carácter afirmativo de Martín Fierro, su efectiva propuesta estética. Ello es confirmado por el propio Girondo cuando dice,

literariamente, por lo menos, puede afirmarse que Martín Fierro nunca tuvo una estética propia, ni remodeló alguno de los tantos 'ismos' mencionados. Divulgó, en cambio, la obra de muchos poetas y escritores de gran repercusión en ese momento - aunque fueran desconocidos entre nosotros- y demostró el fervor con que gran parte de sus colaboradores se adhirió a las tendencias más vivientes y renovadoras. (1999, p. 319)

La pregunta que surge aquí es por qué esa reticencia para definir, aunque más no fuera, algunas de las tendencias estéticas que convivieron en Martín Fierro. Sin respuestas sencillas ni unívocas, aquella negativa contribuye a colocar en primer lugar el carácter generacional de los participantes del periódico, es decir que por sobre cualquier posible postulación estética prevalece algo así como un estado del espíritu que los engloba a todos y frente al que cualquier disidencia en el plano de la concreción resulta anecdótica.

Girondo concede, sin embargo, que Martín Fierro contribuyó a imponer "un cierto tono" a la cultura de su época. Pero si reflexionamos sobre la frase "un cierto tono" observamos que es doblemente imprecisa debido a la indefinición del adjetivo "cierto" que no "colorea" de ningún modo ese tono aludido.

Hacia el final del artículo, al mismo tiempo que reconoce mejoras en el campo cultural, más editoriales, más galerías de arte, más revistas, percibe que se está viviendo un tiempo "exangüe y descreído", que combina la peligrosa ausencia de libertad (hace tres años que gobierna el peronismo) con una creciente corrupción del auténtico anhelo de producir arte. La nostalgia, inevitable, frente a tal panorama permite una invocación al espíritu de Martín Fierro, a esa fuerza, espiritual según definición de Girondo, que había constituido una generación.

Vemos, pues, en esa confrontación final, entre el presente y el pasado, en donde se resaltan apenas mejoras materiales en relación al campo cultural, que Oliverio coherentemente con su rechazo a intentar definiciones de tipo estético, no percibe ni identifica líneas de descendencia. El martinfierrismo, de este modo, se alza ante nosotros como una condición del espíritu, ligada al ímpetu juvenil y a la pureza que esa juventud, supuestamente comporta.

Y son para destacar algunas cuestiones, el carácter juvenil del movimiento, su perfil divulgativo por sobre la construcción de una estética propia, la camaradería por sobre la pelea. Girondo relee aquel período y atribuye al ímpetu de la juventud una actitud, muchas veces, un poco intransigente como cuando, luego de haber trazado un panorama que pinta a Buenos Aires como 
una aldea en donde nunca pasa nada, señala: "Es posible que la falta de perspectiva y la impaciencia juvenil recargasen los tonos quejumbrosos y las tintas ultramortuorias" (1999, p. 304).

En el informe elaborado por Girondo prevalece sobre todo una actitud que se sitúa a mitad de camino entre la nostalgia -este es el tono predominante cuando evoca los años del periódico- y la frustración cuando a partir de su evocación dirige su mirada hacia el presente. Resulta claro que el presente no es de su agrado.

\section{Punto de llegada}

Es posible establecer innumerables cruces entre las evocaciones y los olvidos de estos cuatro participantes de las vanguardias argentinas y brasileñas. Pero entiendo que el principal de ellos, y que traza sin dudas una diferencia entre naciones y proyectos de naciones, es la magnitud otorgada a aquella vivencia, la relevancia artística y política atribuida a las vanguardias. El ejemplo de Oliverio Girondo, con su apología del juvenilismo y con su escamoteo de lo político, con su desvinculación de la relación entre "lengua nacional", "Estado" y "vanguardia" sin duda que colocan al movimiento Martín Fierro en una posición excéntrica en la construcción de la Nación. No resulta anecdótico que los "hijos" de Girondo, Pellegrini, Pizarnik, Llinas, aún hoy constituyan un grupo marginal dentro de la tradición poética argentina, mientras que el Borges que, rápidamente, abjura de la modernidad y la entrega a una suerte de fatalismo, "sólo se puede ser moderno", ha constituido el centro del canon literario argentino. La gravitación, por momentos absoluta, de Borges en nuestro campo cultural, sin dudas ha contribuido de manera decisiva para una determinada apreciación de la vanguardia argentina, puesto que más allá de la debilidad o no de sus manifestaciones, de la originalidad o no de sus contribuciones o de su radicalidad, lo cierto es que nadie se atribuye su legado. Se trata de un "tesoro" que nadie reclama para sí. Ni siquiera nuestra "neovanguardia" nucleada en el Instituto Di Tella durante los años 60 se refirió al período martinfierrista.

Al contrario, tanto el crítico Mário de Andrade como el celebratorio Oswald de Andrade o bien han colocado al modernismo brasileño como el punto de llegada de una "adultez artística" o bien lo han colocado como uno de los períodos más convulsionados de la historia del país que, aunque más no sea como contraespejo, funciona para el futuro. Resulta innegable que aquello que demandaba Girondo, que los más jóvenes se inspiren en el espíritu Martín Fierro, ha funcionado para la cultura brasileña, así lo demuestran las relecturas 
sucesivas del modernismo que hicieron los poetas concretos a fines de los cincuenta, el tropicalismo bahiano a fines de los sesenta y los poetas marginales cariocas a comienzos de los setenta, cada uno a su modo, logró extraer una nueva y renovadora energía de aquel momento. Innumerables tesis académicas se han ocupado de aquel periodo e incontables reediciones críticas de las obras producidas en aquella época. Mientras que en Argentina, una de las primeras publicaciones académicas, Contorno, dirigida, entre otros por Ismael Viñas y David Viñas, se inicia con una demoledora crítica al martinfierrismo. Me refiero al primer número de la revista, aparecido en noviembre de 1953, cuyo título de tapa decía "Los 'martinfierristas': su tiempo y el nuestro" y comenzaba del siguiente modo: "Todo el movimiento 'martinfierrista' exhala una esotérica arrogancia, una altanera presunción de compartir valores intransferibles, de pertenecer a una especie de orden de exclusividad: la francmasonería de la juventud". Aquel ensayo criticaba el concepto de juventud como un valor en sí mismo y adjudicaba al grupo Martín Fierro haber encarnado aquella ideología. Pocos años después vendrán los textos memorialísticos que publicaron Eduardo González Lanuza y Córdova Iturburu, este último en 1962 con un libro titulado La revolución martinfierrista. De ellos, debemos resaltar la importancia historiográfica, aunque el hecho de que ambos hayan formado parte del martinfierrismo nos reafirma en nuestro convencimiento de la escasa recepción y apropiación de aquella experiencia.

\section{Bibliografía citada y consultada:}

AIRA, Cesar. Diccionario de autores latinoamericanos. Buenos Aires: Emece/Ada Korn Editora, 2001.

ANDRADE, Mário de. Paulicéia desvairada. Edición fascsimilar preparada por Jorge Schwarz. S/D.

. O turista aprendiz. Belo Horizonte: Editora Itatiaia, 2002.

. Obra escogida. (Selección, prólogo y notas Gilda de Mello e Souza).

Caracas: Biblioteca Ayacucho, 1979.

ANDRADE, Oswald de. Estética e política. San Pablo: Globo, 1991.

. A utopia antropofágica. San Pablo: Globo, 1990.

. Pau Brasil. Edición facsimilar preprara por Jorge Schwarz. S/D.

- Escritos antropófagos (selección, cronología y postfacio: Alejandra Laera, Gonzalo Moisés Aguilar). Buenos Aires: Corregidor, 2001. 
ANTELO, Raúl. Na ilha de Marapatá (Mário de Andrade lê os hispanoamericanos). San Pablo: Hucitec/MinC/PRÓ-MEMÓRIA, 1986.

BORGES, Jorge Luis. Textos recobrados 1919-1929. Buenos Aires: Emecé, 1997.

. El idioma de los argentinos. Madrid: Alianza Editorial, 1998.

. Obras completas. Buenos Aires: Emecé, 1985.

BORGES, Jorge Luis; FERNÁNDEZ, Macedonio. Correspondencia. Edición al cuidado de Carlos García. Buenos Aires: Corregidor, 2000.

GIRONDO, Oliverio. Obra Completa (Edición crítica Raúl Antelo). Buenos Aires:

Sudamericana, ALLCA XX, 1999.

LAFETÁ, João Luiz. 1930: A crítica e o modernismo. San Pablo: Editora 34, 2000.

SIMÓN, Iumna María. "Vanguardia y tradición en el contexto brasileño". In: Situando a Huidobro. Comp. Ana Pizarro. Santiago de Chile: Ministerio de Educación, División de Extensión Cultural, 1995.

SORRENTINO, Fernando. Siete conversaciones con Jorge Luis Borges. Buenos Aires: Editorial El Ateneo, 2001.

\section{Title:}

Memory exercises: on the reconstruction methods of vanguardist memory in Oswald de Andrade, Jorge Luis Borges, Mário de Andrade and Oliverio Girondo

\section{Abstract:}

This article proposes an analysis of a series of texts of Oswald de Andrade, Jorge Luis Borges, Oliverio Girondo and Mario de Andrade referring to avantgarde productions. The analysis aims to investigate the ways in which, from such testimonies, memories and reflections, it has been thought the literary avant-garde of the twenties in Argentina and Brazil, and placed in their respective cultural fields.

\section{Keywords:}

Avant-garde, memory, cultural field 